\title{
- The Dark Face of Heaven: True Stories of Transcendence Through Trauma
}

\author{
Janet Elizabeth Colli. New York, NY: Random House, LLC, 2014, 232 pages, $\$ 17.00$ (paperback), \$8.04 (Kindle)
}

I was very quickly drawn in by this riveting, iconoclastic, and heartfelt book about how psychotherapy has evolved to support the healing, growth, and evolution of consciousness. Janet Colli has a very positive view of trauma and believes that consciousness expands through healing trauma and that this process can be transformative in the hands of psychotherapists, working as modern-day shamans. Dr. Colli sees trauma as a portal into the subtle realms of consciousness, enlightened states, and even the nondual reality, elevating psychology into the realm of the sacred and numinous.

The book focuses on clinical stories to illustrate how treating traumatic memories with transpersonal and shamanic psychotherapy can truly heal and even evolve us as humans. Dr. Colli's awakened and skillful transpersonal or shamanic psychotherapy includes unconventional use of what she calls eye movement desensitization and reprocessing (EMDR) or bilateral stimulation and time travel, and Jung's active imagination/creative visualization, dream analysis, past life memories, pre- and perinatal memory retrieval, Akashic archives, story and metaphor telling, animal-assisted therapy, and modern shamanism. She relies heavily on Carl Jung's and Stanislav Grof's work and frequently refers to concepts from attachment theory, affect regulation, neurobiology, and neuroplasticity.

The book begins with Dr. Colli introducing herself and her practice, with an interesting overview of the history of transpersonal psychology. She reinforces the spiritual dimension by weaving in names of spiritual teachers in Hinduism, Buddhism, and Christianity. She references the work of Freud, Jung, Groff, and many other contributors to the field of psychology, neurobiology, and cancer research. The introduction would have been the place to explain how she uses EMDR therapy. Throughout the book, her description of EMDR treatment is vague and limited to references to "time travel," bilateral stimulation, and negative and positive cognitions. It is only near the end of the book that she notes that the client's eyes follow her fingers for bilateral stimulation.

After describing various celebrities' traumas, Dr. Colli presents seven clinical stories, which "document the journey from outer trauma to the inner, subtle realms, and its integrative healing function. Such that the inner healed the outer and greatly expanded its reach and compass." The first is her own compelling story of neglect and abuse, her dysfunctional relationship with food, and her recovery from cancer. "My cancer was tantamount to a shamanic illness whereby an initiate is called into training to become a healer herself."

The other stories chronicle six clients' recovery from depression, anxiety, posttraumatic stress disorder, functional dissociation, obesity, shame, suffering, and childhood trauma. They illustrate how Dr. Colli incorporates transpersonal elements such as kundalini energy, near-death experiences, out-of-body experiences, zero-point field, karmic and ancestral debt, afterdeath communication, dissociation as a functional state, totems in shamanism, the numinous potential of dreams, and lucid dreaming. Jungians will appreciate her discussion about uniting the many encapsulated parts of the psyche, including the shadow into a unified whole or oneness (Jung's Self) and how Dr. Colli integrates Jung's concepts of synchronicity, collective unconscious and renewal, the shadow, Self, and regeneration and individuation in her work.

The clinical stories bog down a bit mostly because she doesn't explain the role of therapy, in particular, EMDR therapy. While they lack the rich clinical detail that would be useful and of interest to therapists, the stories effectively illustrate transpersonal phenomena and transcendence. Dr. Colli's written voice is very colloquial, refreshing and accessible, fun and slightly free associative, and her free-flowing style holds the reader's attention well.

REVIEWED BY SHEILA KRYSTAL 